\title{
Further Light on the Tyramine Test in Depression
}

\author{
M. SANDLER, SUSAN BONHAM CARTER, M.A. REVELEY, VIVETTE GLOVER and GLEN REIN
}

SUMMARY: In studies of post-partum women, the oral tyramine loading test is shown to be of predictive value in identifying those subjects with a lifetime history of depressive illness. The cause of the decreased output of conjugated tyramine, after tyramine ingestion, is still unclear. Some possible mechanisms have been under scrutiny.

RESUME: Chez les femmes post-partum, le test de surcharge oral à la tyramine semble avoir une valeur prédictive pour identifier les sujets avec une histoire de maladie dépressive de longue durée. Nous ne savons toujours pas la cause de l'excrétion diminuée de tyramine conjuguée après cette surcharge en tyramine. Nous étudions quelques méchanismes possibles.

Bernhard Baron Memorial Research Laboratories and Institute of Obstetrics and Gynaecology, Queen Charlotte's Maternity Hospital, Goldhawk Road, London W6 OXG, U.K.

Reprint requests to $M$. Sandler, Institute of Obstetrics and Gynaecology. Queen Charlotte's Maternity Hospital, Goldhawk Road, London W6 0XG, U.K.
Patients with unipolar depressive illness excrete significantly lower amounts of conjugated tyramine in response to an oral tyramine load than do controls (Sandler et al., 1975; Bonham Carter et al., 1978a). Because this deficit persisted after some patients had improved or recovered (Bonham Carter et al., 1978a), it seemed possible that it could be a marker of vulnerability to depression, rather than a state-dependent biochemical indicator and thus potentially useful in clinical practice. There is a substantially higher incidence of true depressive illness (as opposed to the "four-day blues") in the extended puerperium compared with other times in a young woman's life (Kendell et al., 1976) and this illness is associated with a raised infant morbidity, if not mortality (Harvey, 1978). To test the hypothesis that the tyramine load test might form a useful predictor for depression, we carried out a prospective study (Bonham Carter et al., 1980) of a group of pregnant women whose psychiatric status was unknown, and compared the top $20 \%$ (15 of 74) of conjugated tyramine excretors after oral challenge, with the bottom 20\%. When these women were interviewed postpartum by a psychiatrist blind to the biochemical findings, those with low output were significantly ( $p=0.014$, Chi Square test) more likely to have a lifetime history of unipolar depression than those in the high output group. Moreover, the lifetime incidence of depression in the low output group was $73 \%$, a rate almost three times higher than that $(27 \%)$ of the high output group, which was not different from a rate $(24 \%)$ found in an age- and sex-matched population study (Weissman and Myers, 1978). While the tyramine excretion test did not distinguish puerperal from non- puerperal depression in this sample, it is interesting to note that all the women with a history of postpartum depression fell into the low tyramine group. As the patients were clinically well both when tyramine excretion was determined and at the time of clinical interview, it does appear that low excretion of conjugated tyramine may be linked to an increased vulnerability to depression.

We do not know the cause of the low excretion of conjugated tyramine in some depressives. One possibility to consider is that there is an increase of monoamine oxidase (MAO) activity in unipolar depression. It might be that overactivity of MAO directs more tyramine along this route, and leaves less available for conjugation. We have just completed a study demonstrating increased platelet MAO activity in unipolar depression (Reveley et al., in preparation), confirming previous studies of platelet MAO in unipolar depression, which have also found either increased (Nies et al., 1971; Landowski et al., 1975; Mann, 1979) or normal values with a trend towards increased (Murphy and Weiss, 1972) activity. While our platelet MAO findings make this an attractive explanation, we (Bonham Carter et al., 1978a) have failed to find an elevation of the acid metabolite of tyramine, deriving from the oxidative deamination of tyramine by MAO, in low tyramine excretors after oral challenge. Since the excretion of this acid metabolite, p-hydroxyphenylacetic acid, is not significantly different in depressives compared with normal subjects, it seems unlikely that the low excretion of conjugated tyramine by the depressive group after oral loading is due to a decreased absorption of tyramine. It also seems unlikely to stem from chronic sulphate depletion. We had 
previously shown that oral inorganic sulphate administration has no effect on oral tyramine conjugation (Bonham Carter et al., 1978b). It is largely unabsorbed from the gastrointestinal tract. However, organic sulphate, in this case cysteine, administered in high dosage $(\mathrm{g} / \mathrm{h}$ for $9 \mathrm{~h})$, brought about a significant increase in conjugated tyramine output after oral loading both in normal and severely depressed subjects. Even so, the percentage increase was no greater in the depressed, poorly-conjugating patients than in the controls, indicating that neither the normal subjects nor the depressed patients are saturated with sulphate and that the depressives are, porportionately, no less saturated than controls (Bonham Carter et al., in preparation).

The conjugation of tyramine with sulphate is catalysed by the enzyme phenolsulphotransferase (PST). This reaction uses 3'-phosphoadenosine-5'phosphosulphate (PAPS), which is generated in the following manner, as sulphate donor:

$$
\begin{array}{lll}
12-\mathrm{ATP}+\mathrm{SO}_{4}^{2-} \rightarrow & \text { APS + } \mathrm{PP}_{\mathrm{i}} \\
\mathrm{APS}+\mathrm{ATP} \rightarrow & \text { PAPS + ADP } \\
\mathrm{PAPS}+\text { tyramine PST } & \text { tyramine-O- } \\
& \begin{array}{l}
\text { sulphate }+ \\
\text { PAP }
\end{array}
\end{array}
$$

(ATP = adenosine triphosphate; APS $=$ adenosine 5'-phosphosulphate; ADP $=$ adenosine diphosphate; PAP $=3$ 'phosphoadenosine-5'-phosphate).

A possible lesion in these depressed patients is a deficiency in the conjugation mechanism itself. PST has recently been found in platelets and we (Rein et al., in preparation) and Hart et al. (1979) have characterised it there and in other human tissues. The enzyme is active with tyramine, dopamine, noradrenaline and adrenaline and has high affinity for these substrates. It also acts on alcohol and acid metabolites of monoamines, such as 4-hydroxy-3-methoxyphenylglycol and homovanillic acid, but with lower affinity. Our present evidence suggests that the same form of the enzyme is present in platelets, intestine and brain, in that the relative order of activity with these different substrates is the same in the different tissues (Rein et al., in preparation). A generalised deficiency in the system, observable indirectly by the oral tyramine test, might, therefore, reflect a disturbance of amine conjugation in other parts of the body including the brain. A rate-limiting step in the production of conjugated tyramine could be the generation of PAPS, which in turn depends on ATP. A generalised depletion of ATP or inability to use ATP could be one explanation of the low output of conjugated tyramine. Another could be a deficiency in one of the enzymes involved. As platelet PST can be used as a marker for that elsewhere, we are currently measuring its activity in the low excretors.

\section{REFERENCES}

BONHAM CARTER, S., GOODWIN, B.L., SANDLER, M., GILLMAN, P.K. and BRIDGES, P.K., in preparation.

BONHAM CARTER, S., REVELEY, M.A. SANDLER, M., DEWHURST, J., LITTLE, B.C., HAYWORTH, J. and PRIEST, R.G. (1980). Decreased output of conjugated tyramine is associated with lifetime vulnerability to depressive illness. Psychiat. Res., in press.
BONHAM CARTER, S., SANDLER, M., GOODWIN, B.L., SEPPING, P. and BRIDGES, P.K. (1978a). Decreased urinary output of tyramine and its metabolites in depression. Br. J. Psychiat. 132, 125-132.

BONHAM CARTER, S., SANDLER, M., SEPPING, P. and BRIDGES, P.K.(1978b). Decreased conjugated tyramine output in depression: gastrointestinal factors. Br. J. Clin. Pharmac., 5, 269-272.

HART, R.F., RENSKERS, K.J., NELSON, E.O. and ROTH, J.A. (1979). Localisation and characterisation of phenol sulfotransferase in human platelets. Life Sci., 24, 125130.

HAR VEY, D. (1978). Maternal mental illness the effect on the baby. In Mental Illness in Pregnancy and the Puerperium. Ed. M. Sandler. Publ. Oxford University Press, Oxford, 112-119.

KENDELL, R.E., WAINWRIGHT, S., HAILEY, A. and SHANNON, B. (1976). The influence of child birth on psychiatric morbidity. Psychol. Med., 6, 297-302.

LANDOWSKI, J., LYSIAK, W., ANGIELSKI, S. (1975). Monoamine oxidase activity in blood platelets from patients with cyclophrenic depressive syndromes. Biochem. Med., 14, 347-354.

MANN, J. (1979). Altered platelet monoamine oxidase activity in affective disorders. Psychol. Med., 9, 729-736.

MURPHY, D.L. and WEISS, R. (1972). Reduced monoamine oxidase activity in blood platelets from bipolar depressed patients. Am. J. Psychiat., 128, 1351-1357.

NIES, A., ROBINSON, D.S., RAVARIS, C.L. and DAVIS, J.M. (1971). Amines and monoamine oxidase in relation to aging and depression in man. Psychosom. Med., 33, 470.

REIN, G., GLOVER, V. and SANDLER, M., in preparation.

REVELEY, M.A., GLOVER, V., SANDLER, $M$. and COPPEN, A., in preparation.

SANDLER, M., BONHAM CARTER, S., CUTHBERT, M.F. and PARE, C.M.B. (1975). Is there an increase in monoamine oxidase activity in depressive illness? Lancet, i, 1045-1049.

WEISSMAN, M.M. and MYERS, J.K. (1978). Affective disorders in a U.S. urban community. Arch. Gen. Psychiat., 35, 1304-1311. 
Canadian Journal

of Neurological Sciences

Please enter my subscription

Name

Address

City

Province

Code
PUBLISHED

QUARTERLY

\section{Subscription Rate}

for One Year

$\$ 24.00$ (Canadian)

$\$ 12.00$ for

students, internes,

pre and post

doctoral fellows

Begin my subscription

Date 


\section{Business reply mail}

Courrier réponse d'affaires

No postage stamp necessary if matled

Se poste sans timbre au Canada

in Canada

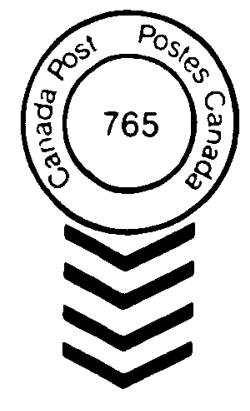

Postage will be paid by

\section{Canadian Journal}

\section{of Neurological Sciences}

GF 543 Health Sciences Centre

700 William Avenue

Winnipeg, Canada

R3E 023 